\title{
In-vivo, hypoglycemic, hypolipidemic and oxidative stress inhibitory activities of Myrtus communis L. fruits hydroalcoholic extract in normoglycemic and streptozotocin-induced diabetic rats.
}

\author{
Sibel Tas ${ }^{1 *}$, Birol Tas ${ }^{2}$, Najlaa Bassalat ${ }^{1}$, Nidal Jaradat ${ }^{3 *}$ \\ ${ }^{1}$ Department of Biology, Arts and Sciences Faculty, Uludağ University, Bursa, Turkey \\ ${ }^{2}$ Department of Park and Horticulture, Vocational School of Technical Sciences, Uludağ University, Bursa, Turkey \\ ${ }^{3}$ Department of Pharmacy, Faculty of Medicine and Health Science, An-Najah National University, Nablus, Palestine
}

\begin{abstract}
Plants with antidiabetic effects are being used in traditional medicine for thousands of years and phytogenic products continue to play an essential part in pharmacy and medicine. The need to investigate highly effective and safe drugs for diabetes mellitus remains a significant challenge for modern medicine. Myrtus communis $\mathbf{L}$. fruits and leaves had medicinal and nutritive properties and were utilized in the traditional medicine as an antidiabetic agent. This study was designed to investigate the hypoglycemic, and hypolipidemic effects of $M$. communis fruits hydroalcoholic extract also pointed toward the assessment of its role in oxidative-antioxidative systems in Streptozotocin-induced (STZ) diabetic rats. Forty male Wistar rats were randomly divided into four groups which were supplemented with $M$. communis fruits hydroalcoholic extract in drinking water for five weeks. The Malondialdehyde levels (MDA) in kidney, heart, liver and muscles tissues were estimated by using spectrophotometer. In addition, the serum insulin levels were assessed by the radioimmunoassay. While, the Total Cholesterol (TC), High-Density Lipoprotein-Cholesterol (HDL-C), Triglyceride (TG), Erythrocyte Superoxide Dismutase (SOD) and whole blood glutathione peroxidase (GSH-Px) were estimated utilizing commercial biochemical kits. The experimental groups of rats which were treated with $M$. communis fruits hydroalcoholic extract showed a reduction in serum glucose, lipid profile, and tissues malondialdehyde levels and an increase in insulin, serum paraoxonase, arylesterase, erythrocyte SOD, and the whole blood GSH-Px activities. These findings suggest that $M$. communis fruit hydroalcoholic extract has hypoglycemic, hypolipidemic and oxidative stress inhibitory activities in STZ-induced diabetic rats. Future studies are needed to address the role of $M$. communis fruits extract on humans that have diabetes.
\end{abstract}

Keywords: Myrtus communis, Diabetes mellitus, Hyperlipidemia, Oxidative stress.

\section{Introduction}

Plants have been a valuable source of therapeutic agents, and still many of today's drugs are plant-derived therapeutic agents or their semisynthetic derivatives [1]. A considerable number of plant species are classified as functional foods due to their curative and preventative therapeutic effects, especially against certain kinds of chronic diseases. In modern medicine, global interest is focusing on this type of plants due to their safety issue. Moreover, these plants have been used from ancient times due to their potential physiological effects, which can reduce the risk of some diseases beyond their fundamental nutritional values [2].

Oxidative stress shows very critical role in the pathogenesis of many diseases including diabetes mellitus complications. Hyperglycemia, abnormal metabolism of lipids, carbohydrates and proteins also decreased in antioxidant defenses, which may cause micro- and macro-vascular complications in later stages [3]. At the normal condition, the oxidant-antioxidant system in the healthy body system is usually controlled and balanced. The risk of cell damage occurs when there is an imbalance between the oxidant-antioxidant defense systems [4].

The presence of the Reactive Oxygen Species (ROS) which consist mainly of singlet oxygen, hydroxyl radicals, superoxide anion $\left(\mathrm{O}^{2-}\right)$, and hydrogen peroxide $\left(\mathrm{H}_{2} \mathrm{O}_{2}\right)$ usually causes oxidative stress [5]. This abnormal physiological stress is controlled by the human aerobic cells by means of enzyme system as Glutathione peroxidase (GSH-Px), Glutathione reductase (GRx), Glutathione (GSH), Catalase (CAT), and Superoxide Dismutase (SOD) enzymes. Also, by external nonenzymatic antioxidants as ascorbate, $\alpha$-tocopherol and 
glutathione, cysteine, thioredoxin, vitamins A, C, E and many polyphenolic compounds which obtained mainly from plant origin [6]. Recently, different plant extracts and functional foods have been widely used by patients who have diabetes, cancer, atherosclerosis and many other diseases, due to their potent natural antioxidant properties without any side effects as compared to synthetic antioxidant pharmaceutical agents [7].

Many herbal remedies used from ancient times continue to be used today to treat diabetes or to reduce its complications. It was reported that the hypoglycemic effects of plants are often occurred due to their ability to potentiate pancreatic $\beta$-cells to produce more insulin or by decreasing the absorption of glucose in the intestinal tract [8].

Myrtus communis L. is commonly known as Myrtle, which is one of the edible food and medicinal plants in the Mediterranean and the Black Sea regions, including Turkey (Adana, Bursa, Mersin, Hatay, Antalya, Çanakkale, Trabzon, Samsun, Sinop, Zonguldak, Çanakkale, İzmir, Muğla, and İstanbul) and grows mainly in swamps and forests. It is a perennial evergreen plant belongs to Myrtaceae family. The plant stems are branched, woody and erect. The flowers are tiny and have white color. The leaves have oval shape and dark green color, while the fruits have berry form with bluish black color [9].

This plant has been used traditionally for the treatment of diabetes, various skin diseases, epistaxis, leucorrhoea, diarrhea, urethritis, peptic ulcers, palpitation, headache, hemorrhoids, inflammation, excessive perspiration, hemorrhage, conjunctivitis, and various pulmonary diseases [10].

However, the edible $M$. communis fruits have a long history of therapeutic uses including anti-inflammatory, antinociceptive, antimicrobial, hypoglycemic, antimutagenic and antioxidant effects [10-14].

Polyphenolic constituent of $M$. communis fruits was characterized by high concentrations of flavanols, flavonols, and flavonol glycosides. Fruits are also reported to contain anthocyanin glucosides, anthocyanin arabinosides, kaempferol, myricetin 3, 3-di-ogalactoside, quercetin, tannin, resins, caffeic, malic and citric acids, sugars, myricetin 3-o-glucoside $[9,15]$.

In addition, $M$. communis fruits were found to be rich in minerals such as $\mathrm{K}, \mathrm{Ca}, \mathrm{Na}, \mathrm{P}$, and $\mathrm{Mg}$, also contain vitamins as vitamins $\mathrm{A}, \mathrm{B} 12, \mathrm{C}, \mathrm{D}$, and $\mathrm{E}$ [16-18].

Nowadays, the trends in the treatment of diabetes are to control blood glucose level and to reduce the complications caused by oxidative stress [19]. The $M$. communis fruits may reduce oxidative stress by reducing blood sugar level and may affect antioxidant enzyme systems. In particular, this study was planned to evaluate the effects of $M$. communis fruits hydroalcoholic extract on oxidant-antioxidant systems in STZinduced diabetic rats, including serum paraoxonase and arylesterase activity. To our knowledge, this is the first trial for investigating the effects of $M$. communis fruits hydroalcoholic extract on antioxidant enzyme system in STZ-induced diabetic rats.

The current investigation aimed to estimate the serum Paraoxonase (PON), Arylesterase (ARE), erythrocyte Superoxide Dismutase (SOD), and blood glutathione peroxidase (GSH-Px) activities to assess the antioxidant mechanisms. Moreover, to investigate the oxidative status in the current study, Malondialdehyde (MDA) levels in tissues as skeletal muscle (Musculus gastrocnemius), heart, liver, and kidney. Also, the lipid profile in blood including Triglyceride (TG), High-Density Lipoprotein-Cholesterol (HDL-C) and Total Cholesterol (TC) levels was estimated in STZ-induced diabetic rats.

\section{Materials and Methods}

\section{Preparing of plant extract}

The fruits of $M$. communis plant were gathered from Yalova, of the Marmara region of Turkey, during the fruiting time, July 2013. The collected fruits were washed well by using tap water and dried at room temperature $\left(25 \pm 2^{\circ} \mathrm{C}\right)$ and humidity $(55 \pm 5$ $\mathrm{RH})$ in the shade for three weeks; then the dried fruits (moisture content $7.75 \%$ ) were grounded into coarse powder (sieve No. 20). The dried extract of $M$. communis fruits powder was carried out by placing $100 \mathrm{~g}$ of plant powder with $500 \mathrm{ml}$ of ethanol/water (70/30) in a percolator for $2 \mathrm{~h}$; then the solvents were evaporated from the extract using a rotavap (Heidolph OB2000, VV2000, Germany).

\section{Preparing of animals}

The experimental protocols, ethical procedures, and policies were authorized according to the Animal Care and Use Committee of Uludağ University under a license number (Karara no; 2015-9/20). In the current study, 40 male Wistar strain rats (age: 4 months) and weighing approximately $350 \mathrm{~g}$ (Wister-albino conventional rats, Harlan Laboratories/ ENVİGO, Holland) were used as experimental animals which obtained from the Uludağ University Experimental Animals Care and Research Center. The rats were kept at room temperature $25 \pm 2{ }^{\circ} \mathrm{C}$, and ambient relative humidity $55 \% \pm 5 \%$ with a 12 h controlled light-dark cycle. Free access to tap water and standard laboratory food was given to rats for one week before starting the experimental part, consisting of proteins 180 $\mathrm{g} / \mathrm{kg}$, fats $25 \mathrm{~g} / \mathrm{kg}$, non-nitrogenous substances $570 \mathrm{~g} / \mathrm{kg}$; crude cellulose $350 \mathrm{~g} / \mathrm{kg}$; crude ash $670 \mathrm{~g} / \mathrm{kg}$, sufficient minerals and vitamins to maintain the health of the rat [20].

\section{Induction of diabetes}

In sodium citrate buffer solution with $\mathrm{pH} 4.5$ was dissolved streptozotocin (Sigma, St. Louis, USA) and induced in rats with a single Intraperitoneal injection (IP) (65 mg/kg STZ). Streptozotocin injection may result in fatal hypoglycemia related to massive insulin release. The rats were kept on a $5 \%$ glucose solution diet for $24 \mathrm{~h}$ after the injection, to avoid fatal hypoglycemia. Control rats received IP injection of sodium 
citrate buffer solution only. After $48 \mathrm{~h}$ of an STZ injection, the blood sugar levels were measured with a diabetes test strips in a glucometer apparatus (Abbott, USA). The animals with a blood glucose levels more than $200 \mathrm{mg} / \mathrm{dL}$ were considered diabetic rats and taken for further experimentation procedures.

\section{Grouping of animals}

All the experimental rats were given an essential diet during the experimental period and separated into four groups (N 10). The first group (C) was a control group and consists of nondiabetic normal rats; the second group contained non-diabetic control rats which administered a $M$. communis fruits hydroalcoholic extract $(\mathrm{C}+\mathrm{MC})$ orally; third group consists of STZ-induced diabetic rats (D); and finally the fourth group included STZ-induced diabetic rats with orally administered of $M$. communis fruit hydroalcoholic extract (D+MC). The hydroalcoholic $M$. communis fruits extract was prepared daily and administered in drinking water at a concentration of $10 \%$ to $(\mathrm{C}+\mathrm{MC})$ and $(\mathrm{D}+\mathrm{MC})$ groups for five weeks after $48 \mathrm{~h}$ from STZ injection.

\section{Sample preparation}

At the end of the experimental period, the blood samples were taken by a cardiac puncture under a light ether anesthesia after 10-12 h of fasting. Blood samples were drawn in non-additive, heparin-coated, and EDTA-containing tubes. A part of the whole blood sample was frozen for GSH-Px determination also the erythrocytes which used for SOD determination were with a standard normal saline solution and frozen after hemolysis. Blood samples were stored at $-20^{\circ} \mathrm{C}$ until further analysis procedures. Immediately after blood collection, the heart, kidney, liver, and musculus gastrocnemius skeletal muscle tissues were removed, rinsed with a standard saline cold solution, dried using sterile gauze, and then kept at $-20^{\circ} \mathrm{C}$ for further use [20].

\section{Analytical methods}

The HDL-C, TG, and TC levels were estimated by standard laboratory methods using an auto-analyzer (Aeroset system Abbott, USA). Meanwhile, the serum insulin level was measured by using ELISA kits (Diagnostic Prod. Corp., USA). Also, by cutting the tails of rats every week for $30 \mathrm{~d}$ of the experiment, the blood glucose values were measured with a diabetes test strips in a glucometer apparatus (Abbott, USA). The PON activity was evaluated by a method of Eckerson et al. [21]. Briefly, the paraoxon hydrolysis rate was measured using Ultraviolet-visible (UV-Vis) spectrophotometer (Shimadzu 1601 and quot, Japan) by monitoring the increase in absorbance at $412 \mathrm{~nm}$ and $25^{\circ} \mathrm{C}$. The PON potentials were expressed as $\mathrm{U} / \mathrm{L}$, and one unit of paraoxonase activity is defined as $1 \mu \mathrm{mol}$ of p-nitrophenol generated per min. Also, the ARE activity was measured by the method of Haagen and Brock [22]. The phenyl acetate was used as a substrate for measuring the ARE potential. Hydrolysis of phenyl acetate to p-nitrophenol was monitored at $412 \mathrm{~nm}$ using UV-Vis spectrophotometer (Shimadzu 1601 and quot, Japan). One unit of ARE activity is defined as $1 \mathrm{mmol}$ of phenol that is generated per minute under the above conditions and expressed as $\mathrm{kU} / \mathrm{L}$ serum [23]. Moreover, the erythrocyte SOD and whole blood GSH-Px activities were assessed using commercial kits (Randox, United Kingdom). The determination of SOD activity was based on the production of superoxide anions by a xanthine/xanthine oxidase system while the GSH-Px catalyses the oxidation of glutathione by cumene hydroperoxide and all the obtained results were expressed as U/ml. The tissues MDA levels were estimated by using the thiobarbituric acid method, by measuring the absorbance values at $532 \mathrm{~nm}$. The specific activities were expressed as nmol MDA/mg per tissue [24].

\section{Statistical analysis}

All the obtained results were analysed using the SPSS 13.0 (IBM Corporation, NY, USA) statistical package and the achieved data as mean \pm SEM were assessed by using Kruskal Wallis test. Also, the differentiation between groups was analysed using Mann-Whitney $U$ test, while the (p-values smaller than 0.05 ) were considered statistically significant.

\section{Results}

The results in Table 1 showed that the food consumptions, water intakes, blood TG, glucose, and TC levels significantly increased in the (D) group $(\mathrm{p}<0.05)$ as compared with other studied groups. While the rat's body weights, insulin, and HDL-C levels significantly decreased $(\mathrm{p}<0.05)$ in comparison with the $\mathrm{C}$ group. Also in the $(\mathrm{C}+\mathrm{MC})$ group, the food and water fluid consumptions significantly increased $(p<0.05)$ in comparison with the $(C)$ group. Moreover, in the $(\mathrm{D}+\mathrm{MC})$ experimental group the blood glucose levels significantly decreased and serum insulin level was significantly increased in comparison with D group. Furthermore, the serum TC and TG levels were notably decreased in $(\mathrm{D}+\mathrm{MC})$ group compared with the D group $(\mathrm{p}<0.05)$.

Additionally, Table 2 showed that the PON and ARE enzymes activities in the (D) group were significantly decreased in comparison with the $(C)$ group $(p<0.05)$. However, these parameters were significantly increased both in the $(\mathrm{C}+\mathrm{MC})$ and $(\mathrm{D}+\mathrm{MC})$ groups compared with the $(\mathrm{C})$ and $(\mathrm{D})$ groups $(p<0.05)$. Moreover, in the (D) group the blood GSH-Px and erythrocyte SOD activities were significantly higher than (C) group $(\mathrm{p}<0.05)$. The presence of $M$. communis fruit extract caused a significant increase in whole blood GSH-Px and erythrocyte SOD enzyme activities $(\mathrm{p}<0.05)$ in the $(\mathrm{C}+\mathrm{MC})$ and $(\mathrm{D}+\mathrm{MC})$ groups in comparison with the $\mathrm{C}$ and $\mathrm{D}$ groups $(\mathrm{p}<0.05)$.

In fact, the MDA levels in the heart, skeletal muscle, kidney, and liver tissues were significantly increased in the (D) group in comparison with the $\mathrm{C}$ group $(\mathrm{p}<0.05)$. However, due the presence of $M$. communis fruits extract in treatments groups $(\mathrm{C}$ $+\mathrm{MC})$ and $(\mathrm{D}+\mathrm{MC})$ reduced the tissues MDA levels in comparison with the $(\mathrm{C})$ and $(\mathrm{D})$ groups $(\mathrm{p}<0.05)$ significantly as revealed in Figures 1-4. 


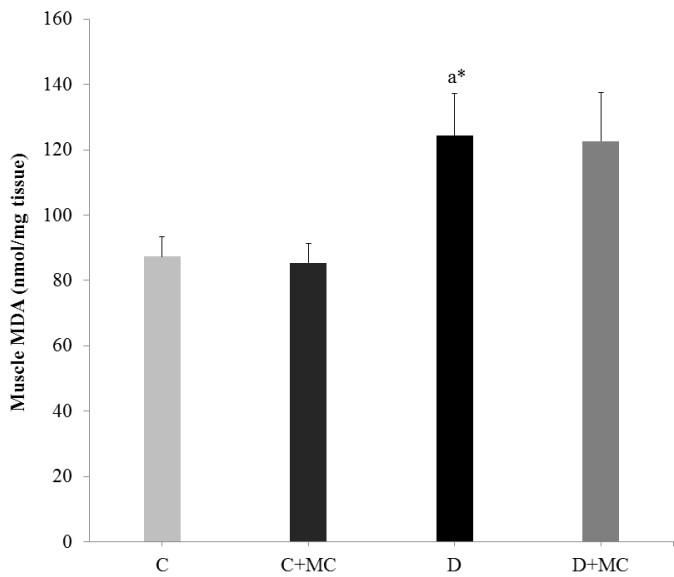

Figure 1. Malondialdehyde (MDA) levels in skeletal muscles tissues (nmol/mg tissue) of the control and experimental rats. The values are expressed as mean \pm SEM (Standard Error of Mean) for eight rats in each group. Statistical comparison: a: compared with the C group, $b$ : compared with the D group. Statistical significance, $p<0.05$.

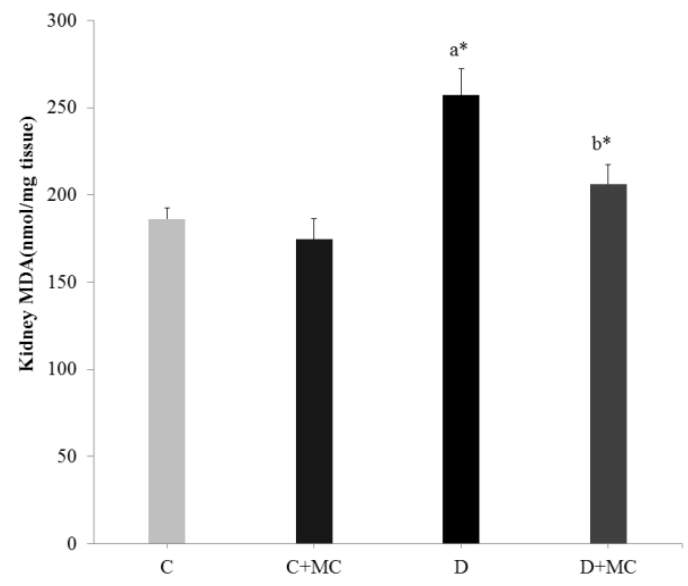

Figure 2. Malondialdehyde (MDA) levels in kidney tissues (nmol/mg tissue) of the control and experimental rats. The values are expressed as mean \pm SEM (Standard Error of Mean) for eight rats in each group. Statistical comparison: a: compared with the $C$ group, $b$ : compared with the D group. Statistical significance, $p<0.05$.

Table 1. Food and fluid intakes, body weight, blood glucose, plasma insulin, Total Cholesterol (TC), Triglyceride (TG) and High-Density Lipoprotein-Cholesterol $(H D L-C)$ levels in control and experimental groups of rats.

\begin{tabular}{lllll}
\hline & C & C+MC & D & D+MC \\
\hline $\begin{array}{l}\text { Food consumption } \\
\text { h) }\end{array}$ & $18 \pm 1$ & $24 \pm 3^{\mathrm{a}^{*}}$ & $35 \pm 1^{\mathrm{a}^{*}}$ & $28 \pm 1^{\mathrm{b}^{*}}$ \\
\hline Water intake (ml/24 h) & $27 \pm 1$ & $38 \pm 1 \mathrm{a}^{* *}$ & $150 \pm 1^{\mathrm{a}^{*}}$ & $121 \pm 1^{\mathrm{b}^{*}}$ \\
\hline Body weight (g) & $352 \pm 2$ & $354 \pm 3$ & $235 \pm 18^{\mathrm{a}^{*}}$ & $365 \pm 8^{\mathrm{b}^{*}}$ \\
\hline Glucose (mg/dL) & $128 \pm 3$ & $123 \pm 1$ & $410 \pm 8^{\mathrm{a}^{*}}$ & $346 \pm 7^{\mathrm{b}^{*}}$ \\
\hline Insulin (ng/ml) & $2.1 \pm 0.1$ & $2.2 \pm 0.3$ & $0,63 \pm 0.2 \mathrm{a}^{*}$ & $1.6 \pm 0.2^{\mathrm{b}^{*}}$ \\
\hline TC (mg/dL) & $110 \pm 3$ & $105 \pm 4$ & $176 \pm 2 \mathrm{a}^{*}$ & $141 \pm 3^{\mathrm{b}^{*}}$ \\
\hline
\end{tabular}

\begin{tabular}{lllll}
\hline TG $(\mathrm{mg} / \mathrm{dL})$ & $56 \pm 3$ & $54 \pm 1$ & $130 \pm 2 \mathrm{a}^{*}$ & $111 \pm 4 \mathrm{~b}^{*}$ \\
\hline HDL-C (mg/dL) & $42 \pm 4$ & $45 \pm 2$ & $27 \pm 4 \mathrm{a}^{*}$ & $30 \pm 2$
\end{tabular}

Values are expressed as mean + S.E.M. (Standard Error of Mean) for 10 rats in each group. ${ }^{a}$ Compared with control group, ${ }^{b}$ Compared with diabetic group. Statistical significance: ${ }^{*} p<0.05 ;{ }^{* *} p<0.01$.

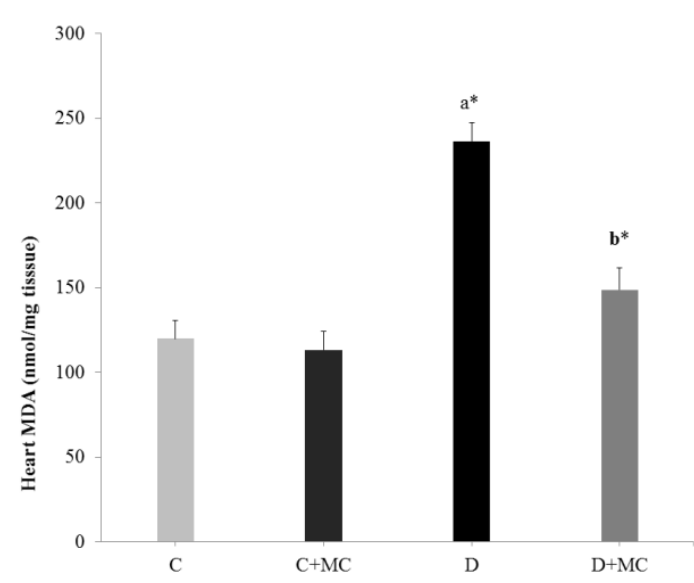

Figure 3. Malondialdehyde (MDA) levels in heart tissues (nmol/mg tissue) of the control and experimental rats. The values are expressed as mean \pm SEM (Standard Error of Mean) for eight rats in each group. Statistical comparison: a: compared with the $C$ group, $b$ : compared with the D group. Statistical significance, $p<0.05$.

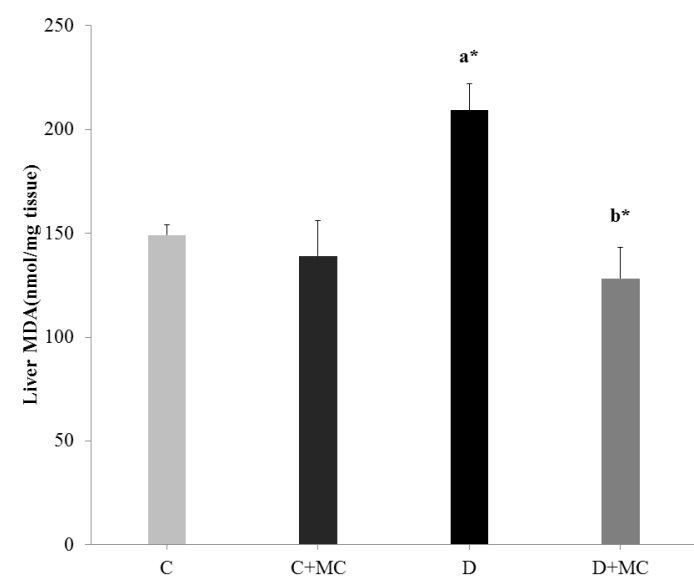

Figure 4. Malondialdehyde (MDA) levels in liver tissues (nmol/mg tissue) of the control and experimental rats. The values are expressed as mean \pm SEM (Standard Error of Mean) for eight rats in each group. Statistical comparison: a: compared with the $C$ group, $b$ : compared with the D group. Statistical significance, $p<0.05$.

Table 2. Glutathione peroxidase (GSH-Px) and erythrocyte Superoxide Dismutase (SOD), Serum Paraoxonase (PON) and Arylesterase Activities (ARE) in all experimental groups.

\begin{tabular}{lllll}
\hline & C & C+MCE & D & D+MCE \\
\hline Blood GSH-Px $(U / m L)$ & $13 \pm 4$ & $15 \pm 1$ & $20 \pm 1^{a^{*}}$ & $28 \pm 2^{b^{*}}$ \\
\hline Erythrocyte SOD $(U / m L)$ & $62 \pm 3$ & $74 \pm 5^{a^{*}}$ & $109 \pm 5^{a^{*}}$ & $144 \pm 3^{\mathrm{b}^{*}}$ \\
\hline PON (U/L) & $121 \pm 3$ & $141 \pm 5^{\mathrm{a}^{*}}$ & $58 \pm 3^{\mathrm{a}^{*}}$ & $128 \pm 6^{\mathrm{b}^{*}}$ \\
\hline
\end{tabular}




\begin{tabular}{|c|c|c|c|c|}
\hline ARE (U/L) & $148 \pm 1$ & $189 \pm 3^{a^{*}}$ & $68 \pm 8^{a^{*}}$ & $86 \pm 3^{b^{*}}$ \\
\hline
\end{tabular}

\section{Discussion}

In the current investigation, it was observed a significant reduction of the blood glucose levels and elevation of serum insulin levels in (D+MC) group. These may occur due to the presence of biologically active phytochemicals in $M$. communis fruit, especially flavonoids and other phenolic molecules. This may act either by increasing of the insulin secretion (by improving the performance of pancreas), by reducing insulin resistance (accelerating glucose uptake and glucose metabolism) or by diminishing glucose absorption from the intestines [25].

In fact, flavonoids act on various molecular targets and regulate different signaling pathways in pancreatic $\beta$-cells, adipocytes, hepatocytes, and skeletal myofibers. They may exert beneficial effects in diabetes by (i) enhancing insulin secretion and reducing apoptosis and promoting proliferation of pancreatic $\beta$-cells, (ii) improving hyperglycemia through regulation of glucose metabolism in hepatocytes, (iii) reducing insulin resistance, inflammation and oxidative stress in muscle and fat, and (iv) increasing glucose uptake in skeletal muscle and white adipose tissue). Flavonoids were shown to regulate carbohydrate digestion, insulin secretion, insulin signaling, and glucose uptake in insulin-sensitive tissues through various intracellular signaling his review highlights recent findings on the anti-diabetic effects of dietary flavonoids, including flavan-3-ols, flavanones, flavonols, anthocyanidins, flavones, and isoflavones, with particular emphasis on the studies that investigated the cellular and molecular mechanisms involved in the beneficial effects of the compounds pathways [25-28].

Previously, Elfellah et al. reported that the administration of $M$. communis extract $(2 \mathrm{~g} / \mathrm{kg})$ which given intragastrically within $30 \mathrm{~min}$ before STZ induction, discarded the initial hyperglycemic effect [10]. Furthermore, Ozkol et al. found a decrease in blood glucose levels at $28^{\text {th }}$ and $35^{\text {th }} \mathrm{d}$ after administration of $M$. communis for STZ-induced diabetic rats [29].

In fact, the increased levels of TC, TG and HDL-C in diabetes mellitus considered a significant risk factor for the development of atherosclerotic heart disease [30-32].

In this study, observed that the plasma levels of TC and TG decreased in the $(\mathrm{D}+\mathrm{MC})$ group in comparison with the (D) group. This reduction may be related to the presence of polyphenols and anthocyanins components in M. communis fruits. However, various studies have shown that these components have a wide range of biological activities, such as antioxidant and antiatherosclerotic activities in cellular, in-vitro and in in-vivo models [10,14,33-36].

In fact, many previously conducted studies revealed that the diet supplements which are rich in anthocyanins molecules or anthocyanins extracts, decreased the serum TG, TC, and increased the serum HDL-C and apolipoprotein A-I (apo A-I) in different animal models [37-41].

Moreover, polyphenol substances could positively affect the uptake of lipid species from the intestine by manipulation of the microbiota composition [42]. Experimentally, polyphenols have been shown to enhance the $\beta$-oxidation in the liver by the increase of the utilization of fatty acids as an energy source $[42,43]$. In the same line, Ozkol et al. [35] reported that the supplements of $M$. communis extract may improve hypolipidemic effects by reducing the blood levels of TC, TG, VLDL-C, LDL-C [29]. Accordingly, the hypolipidemic effect of this extracts may be related to their reducing impacts on cholesterologenesis and fatty acid synthesis.

The current study found that the $M$. communis fruits hydroalcoholic extract have hypolipidemic property in diabetic rats which may be very crucial in preventing or treating of diabetes complications particularly atherosclerotic heart diseases. Hyperlipidemic and hyperglycemic activities which demonstrated in the current investigation may be associated with the oxidative stress which generated MDA, induced lipid peroxidation and caused cells injuries [44-46].

In addition, the current research showed that the MDA levels in the liver, kidney, heart, and skeletal muscle tissues increased in diabetic rats, which affected on the oxidative stress and these findings are consistent with other previous studies $[20,47,48]$.

However, tissue MDA levels were significantly reduced in $(\mathrm{C}$ $+\mathrm{MC})$ and $(\mathrm{D}+\mathrm{MC})$ groups in comparison with their control groups.

Moreover, other study demonstrated a protective effect of $M$. communis for different tissues and organs such as erythrocyte, plasma, lens, and retina by lowering the MDA concentrations $[29,49]$. These changes may be related to hypolipidemic, hypoglycemic and direct antioxidant effects of M. communis. Furthermore, the current investigation focused on evaluation PON1 activity (paraoxonase and arylesterase). Antioxidant enzymes Paraoxonase (PON1) is a serum esterase enzyme which synthesized by the liver and has Paraoxonase (PON) and Arylesterase (ARE) activities which can protect both lowdensity lipoprotein (LDL) and High-Density Lipoprotein (HDL) from oxidative modification [50].

Moreover, PON1 plays a protective or/and preventive role in the progression of atherosclerosis, a risk factor for diseases such as diabetes mellitus or chronic renal failure [51]. In fact, many previous studies suggested that PON and ARE activities can reduce diabetes mellitus complications [20,47,52]. However, other studies indicated that the inactivation of antioxidant enzymes such as PON1 might be prevented by the addition of antioxidant vitamins or herbal supplements [53-55].

The current research presented a significant decrease in (PON) and (ARE) activities in the (D) group. The decrease in PON activity in diabetic rats may be due to glycosylation of the PON1 enzyme. Also, showing that (PON) and (ARE) activities 
were significantly increased in $(\mathrm{C}+\mathrm{MC})$ and $(\mathrm{D}+\mathrm{MC})$ groups as compared with their control groups.

It is well known that the increase of glucose levels and the decrease of antioxidant capacity as shown in the current study in diabetes mellitus may cause oxidative stress by increasing the oxidation of lipids and thus may cause atherosclerotic heart disease. Apparently, the M. communis fruits extract has a potent antioxidant property which can be able to protect lipoprotein (HDL) and PON1 against oxidation and therefore atherosclerosis.

Moreover, in diabetes mellitus, the rise of glucose levels may be merely inactive the active antioxidant enzymes such as SOD and GSH-Px. Ozkol et al., suggested that M. communis fruit extract cause increase erythrocyte, lens and retina GSH levels in STZ-induced diabetic rats [29]. The current study found an increase in erythrocyte SOD and whole GSH-Px activities in (D) group in comparison with (C) group. Thus escalation indicates a rise in the Reactive Oxygen Species (ROS). Hyperglycemic conditions of diabetes not only produce excessive ROS but also impair the antioxidant defense system [56].

The increase of these antioxidant enzymes activities may be due to an excessive compensatory response of ROS production in diabetes. The $M$. communis fruit extract increases the whole GSH-Px activities and erythrocyte SOD activities in the $(\mathrm{C}$ $+\mathrm{MC})$ and $(\mathrm{D}+\mathrm{MC})$ comparing with the (C) and (D) groups. However, the direct stimulation effect of $M$. communis fruit extract on the activities of these antioxidant enzymes in diabetic and normal conditions as well as the studied plant is rich in phenolic compounds which have potential in-vivo antioxidant activity. For example, Devi et al. reported that the anthocyanins could act as antioxidants by direct reduction of free radicals and prevention of oxidative damage to DNA [57]. In addition, Cho et al. found that the antioxidant effects of anthocyanins included regenerating other antioxidants, enhancing antioxidant enzyme activity, and increasing mRNA expression of these enzymes [58].

Summarily, the studied $M$. communis fruits hydroalcoholic extract increased insulin secretion and decreased blood glucose and lipid levels in $(\mathrm{D}+\mathrm{MC})$ group. At the same time, the increase in PON, ARE, erythrocyte SOD and whole blood GSH-Px enzyme activities in both $(\mathrm{C}+\mathrm{MC})$ and $(\mathrm{D}+\mathrm{MC})$ groups. These potentials in serum PON, ARE, whole blood GSH-Px and erythrocyte SOD enzymes activities may play a protective role against the most common complications of diabetes such as acute coronary syndrome and atherogenesis.

\section{Conclusion}

The hydroalcoholic extract of $M$. communis fruits increased the insulin secretion and decreased the blood glucose and lipid levels in the diabetic rats. At the same time, increased PON and ARE, erythrocyte SOD whole blood GSH-PX enzyme activities in the control rats also in the diabetic rats which treated with M. communis fruits hydroalcoholic extract. All these results suggested that the $M$. communis fruits hydroalcoholic extract has hypoglycemic and hypolipidemic and strong antioxidant properties and may be a promising adjunct to ameliorate oxidative stress in STZ-induced diabetic rats. However, to investigate the role of $M$. communis fruit hydroalcoholic extract reinforcement, different doses and accordingly different administration times have to be examined.

\section{Acknowledgments}

N/A

\section{Competing of Interests}

The authors declare that they have no financial and/or nonfinancial competing interests.

\section{Consent for Publication}

All authors gave their consent for the publication of the manuscript for Sibel Taş and Nidal Jaradat to be the corresponding authors.

\section{References}

1. Atanasov AG, Waltenberger B, Pferschy-Wenzig E-M, Linder T, Wawrosch C, Uhrin P, Temml V, Wang L, Schwaiger S, Heiss EH. Discovery and resupply of pharmacologically active plant-derived natural products: a review. Biotechnol Adv 2015; 33: 1582-1614.

2. Saad B, Zaid H, Shanak S, Kadan S. Introduction to medicinal plant safety and efficacy. USA Springer 2017.

3. Rochette L, Zeller M, Cottin Y, Vergely C. Diabetes, oxidative stress and therapeutic strategies. Biochimica et Biophysica Acta (BBA)-General Subjects 2014; 1840: 2709-2729.

4. Rahal A, Kumar A, Singh V, Yadav B, Tiwari R, Chakraborty S, Dhama K. Oxidative stress, prooxidants, and antioxidants: the interplay. Biomed Res Int 2014; 2014: 1-19.

5. Saed-Moucheshi A, Shekoofa A, Pessarakli M. Reactive oxygen species (ROS) generation and detoxifying in plants. J Plant Nutr 2014; 37: 1573-1585.

6. Matough FA, Budin SB, Hamid ZA, Alwahaibi N, Mohamed J. The role of oxidative stress and antioxidants in diabetic complications. Sultan Qaboos Univ Med J 2012; 12: 5-12.

7. Shi J, Moy JH. Functional foods from fruit and fruit products. USA: CRC Press; 2005.

8. Tiwari N, Thakur A, Kumar V, Dey A, Kumar V. Therapeutic targets for diabetes mellitus: an update. Clin Pharmacol Biopharmac 2014; 3: 1-10.

9. Sumbul S, Ahmad MA, Asif M, Akhtar M. Myrtus communis Linn.-a review. Indian J Nat Prod Resour 2011; 2: 395-402.

10. Elfellah M, Akhter M, Khan M. Anti-hyperglycaemic effect of an extract of Myrtus communis in streptozotocin- 
induced diabetes in mice. J Ethnopharmacol 1984; 11: 275-281.

11. Pirbalouti AG, Mirbagheri H, Hamedi B, Rahimi E. Antibacterial activity of the essential oils of myrtle leaves against Erysipelothrix rhusiopathiae. Asian Pac J Trop Biomed 2014; 4: 505-509.

12. Hosseinzadeh $\mathrm{H}$, Khoshdel $\mathrm{M}$, Ghorbani $\mathrm{M}$. Antinociceptive, anti-inflammatory effects and acute toxicity of aqueous and ethanolic extracts of Myrtus communis L. aerial parts in mice. J Acupunct Meridian Stud 2011; 4: 242-247.

13. Djenane D, Yangüela J, Amrouche T, Boubrit S. Chemical composition and antimicrobial effects of essential oils of Eucalyptus globulus, Myrtus communis and Satureja hortensis against Escherichia coli O157: H7 and Staphylococcus aureus in minced beef. Food Sci Technol Int 2011; 17: 505-515.

14. Mimica-Dukic N, Bugarin D, Grbovic S, Mitic-Culafic D, Vukovic-Gacic B, Orcic D, Jovin E, Couladis M. Essential oil of Myrtus communis L. as a potential antioxidant and antimutagenic agents. Molecules 2010; 15: 2759-2770.

15. Akin M, Aktumsek A, Nostro A. Antibacterial activity and composition of the essential oils of Eucalyptus camaldulensis Dehn. and Myrtus communis L. growing in Northern Cyprus. Afr J Biotechnol 2010; 9: 111-116.

16. Haciseferogulları H, Ozcan MM, Arslan D, Unver A. Biochemical compositional and technological characterizations of black and white myrtle (Myrtus communis L.) fruits. J Food Sci Technol 2012; 49: 82-88.

17. Kalt W, Forney CF, Martin A, Prior RL. Antioxidant capacity, vitamin $\mathrm{C}$, phenolics, and anthocyanins after fresh storage of small fruits. J Agr Food Chem 1999; 47: 4638-4644.

18. Der ÇTGB. Total phenolic content and antioxidant properties of various extracts of Myrtle (Myrtus communis L.) berries. Cukurova J Agric Food Sci 2016; 31: 43-50.

19. Giacco F, Brownlee M. Oxidative stress and diabetic complications. Circ Res 2010; 107: 1058-1070.

20. Tas S, Sarandol E, Ayvalik SZ, Serdar Z, Dirican M. Vanadyl sulfate, taurine, and combined vanadyl sulfate and taurine treatments in diabetic rats: effects on the oxidative and antioxidative systems. Arch Med Res 2007; 38: 276-283.

21. Eckerson HW, Wyte CM, La Du B. The human serum paraoxonase/arylesterase polymorphism. Am J Hum Genet 1983; 35: 1126-1138.

22. Haagen L, Brock A. A new automated method for phenotyping arylesterase (EC 3.1. 1.2) based upon inhibition of enzymatic hydrolysis of 4-nitrophenyl acetate by phenyl acetate. Clin Chem Lab Med 1992; 30: 391-396.

23. Fairbanks V. Biochemical aspects of hematology. Philadelphia: W.B. Saunders Co. 1994.
24. Ohkawa H, Ohishi N, Yagi K. Assay for lipid peroxides in animal tissues by thiobarbituric acid reaction. Anal Biochem 1979; 95: 351-358.

25. Testa R, Bonfigli AR, Genovese S, De Nigris V, Ceriello A. The possible role of flavonoids in the prevention of diabetic complications. Nutrients 2016; 8: 310.

26. Putta S, Yarla N, Kumar E, Lakkappa D, Kamal M, Scotti L, Scotti M, Ashraf G, Barreto G, Rao B. Preventive and therapeutic potentials of anthocyanins in diabetes and associated complications. Curr Med Chem 2017; 25: 1-25.

27. Sancho RAS, Pastore GM. Evaluation of the effects of anthocyanins in type 2 diabetes. Food Res Int 2012; 46: 378-386.

28. Różańska D, Regulska-Ilow B. The significance of anthocyanins in the prevention and treatment of type 2 diabetes. Adv Clin Exp Med 2018; 27: 135-142.

29. Ozkol H, Tuluce Y, Dilsiz N, Koyuncu I. Therapeutic potential of some plant extracts used in Turkish traditional medicine on streptozocin-induced type 1 diabetes mellitus in rats. J Membr Biol 2013; 246: 47-55.

30. Natali A, Baldi S, Bonnet F, Petrie J, Trifirò S, Tricò D, Mari A, Investigators R. Plasma HDL-cholesterol and triglycerides, but not LDL-cholesterol, are associated with insulin secretion in non-diabetic subjects. Metabolism 2017; 69: 33-42.

31. Márk L, Dani G. Diabeteses dyslipidaemia és atherosclerosis. Orv Hetil 2016; 157: 746-752.

32. Nakamura A, Monma Y, Kajitani S, Noda K, Nakajima S, Endo H, Takahashi T, Nozaki E. Effect of glycemic state on postprandial hyperlipidemia and hyperinsulinemia in patients with coronary artery disease. Heart Vessels 2016; 31: 1446-1455.

33. Hayder N, Bouhlel I, Skandrani I, Kadri M, Steiman R, Guiraud P, Mariotte AM, Ghedira K, Dijoux-Franca MG, Chekir-Ghedira L. In vitro antioxidant and antigenotoxic potentials of myricetin-3-o-galactoside and myricetin-3-orhamnoside from Myrtus communis: modulation of expression of genes involved in cell defence system using cDNA microarray. Toxicol In Vitro 2008; 22: 567-581.

34. Guo H, Ling W. The update of anthocyanins on obesity and type 2 diabetes: experimental evidence and clinical perspectives. Rev Endocrine Metabolic Disorders 2015; 16: 1-13.

35. Cassidy A, Mukamal KJ, Liu L, Franz M, Eliassen AH, Rimm EB. High anthocyanin intake is associated with a reduced risk of myocardial infarction in young and middle-aged women clinical perspective. Circulation 2013; 127: 188-196.

36. Liu Y, Li D, Zhang Y, Sun R, Xia M. Anthocyanin increases adiponectin secretion and protects against diabetes-related endothelial dysfunction. Am J Physiol Endocrinol Metab 2014; 306: 975-988.

37. Wu T, Tang Q, Yu Z, Gao Z, Hu H, Chen W, Zheng X, Yu T. Inhibitory effects of sweet cherry anthocyanins on the obesity development in C57BL/6 mice. Int $\mathrm{J}$ Food Sci Nutr 2014; 65: 351-359. 
38. Murase T, Nagasawa A, Suzuki J, Hase T, Tokimitsu I. Beneficial effects of tea catechins on diet-induced obesity: stimulation of lipid catabolism in the liver. Int $\mathrm{J}$ Obes 2002; 26: 1459.

39. Morrison MC, Liang W, Mulder $\mathrm{P}$, Verschuren L, Pieterman E, Toet K, Heeringa P, Wielinga PY, Kooistra T, Kleemann R. Mirtoselect, an anthocyanin-rich bilberry extract, attenuates non-alcoholic steatohepatitis and associated fibrosis in ApoE 3Leiden mice. J Hepatol 2015; 62: 1180-1186.

40. Hursel R, Westerterp-Plantenga MS. Catechin-and caffeine-rich teas for control of body weight in humans. Am J Clin Nutr 2013; 98: 1682-1693.

41. Stote KS, Baer DJ. Tea consumption may improve biomarkers of insulin sensitivity and risk factors for diabetes. Int J Nutr 2008; 138: 1584-1588.

42. Wang S, Moustaid-Moussa N, Chen L. Novel insights of dietary polyphenols and obesity. J Nutr Biochem 2014; 25: $1-18$.

43. Takahashi A, Shimizu H, Okazaki Y, Sakaguchi H, Taira T, Suzuki T, Chiji H. Anthocyanin-rich phytochemicals from aronia fruits inhibit visceral fat accumulation and hyperglycemia in high-fat diet-induced dietary obese rats. J Oleo Sci 2015; 64: 1243-1250.

44. Samarghandian S, Borji A, Farkhondeh T. Attenuation of oxidative stress and inflammation by Portulaca oleracea in streptozotocin-induced diabetic rats. J Evid Based Complementary Altern Med 2017; 22: 562-566.

45. de Souza Bastos A, Graves DT, de Melo Loureiro AP, Júnior CR, Corbi SCT, Frizzera F, Scarel-Caminaga RM, Câmara NO, Andriankaja OM, Hiyane MI. Diabetes and increased lipid peroxidation are associated with systemic inflammation even in well-controlled patients. J Diabetes Complications 2016; 30: 1593-1599.

46. Ali F, Naqvi SAS, Bismillah M, Wajid N. Comparative analysis of biochemical parameters in diabetic and nondiabetic acute myocardial infarction patients. Indian Heart J 2016; 68: 325-331.

47. Tas S, Sarandol E, Ziyanok S, Aslan K, Dirican M. Effects of green tea on serum paraoxonase/arylesterase activities in streptozotocin-induced diabetic rats. Nutr Res 2005; 25: 1061-1074.

48. Tas S, Celikler S, ZiyanokAyvalik S, Sarandol E, Dirican M. Ulva rigida improves carbohydrate metabolism, hyperlipidemia and oxidative stress in streptozotocininduced diabetic rats. Cell Biochem Funct 2011; 29: 108-113.

49. Sepici-Dincel A, Acikgoz S, Cevik C, Sengelen M, Yesilada E. Effects of in vivo antioxidant enzyme activities of myrtle oil in normoglycaemic and alloxan diabetic rabbits. J Ethnopharmacol 2007; 110: 498-503.

50. Mackness MI, Mackness B, Durrington PN, Connelly PW, Hegele RA. Paraoxonase: biochemistry, genetics and relationship to plasma lipoproteins. Curr Opin Lipidol 1996; 7: 69-76.

51. Singh K, Singh R, Chandra S, Tyagi S. Paraoxonase-1 is a better indicator than HDL of atherosclerosis-a pilot study in North Indian population. Diabetes Metab Syndr 2017; 16.

52. Tas S, Celikler S, ZiyanokAyvalik S, Sarandol E, Dirican M. Ulva rigida improves carbohydrate metabolism, hyperlipidemia and oxidative stress in streptozotocininduced diabetic rats. Cell Biochem Funct 2011; 29: 108-113.

53. Jarvik GP, Tsai NT, McKinstry LA, Wani R, Brophy VH, Richter RJ, Schellenberg GD, Heagerty PJ, Hatsukami TS, Furlong CE. Vitamin $\mathrm{C}$ and $\mathrm{E}$ intake is associated with increased paraoxonase activity. Arterioscler Thromb Vasc Biol 2002; 22: 1329-1333.

54. Aviram M, Kaplan M, Rosenblat M, Fuhrman B. Dietary antioxidants and paraoxonases against LDL oxidation and atherosclerosis development. Atherosclerosis: Diet and Drugs. USA Springer 2005; 263-300.

55. Taş S, Sarandol E, Dirican M. Vitamin B6 supplementation improves oxidative stress and enhances serum paraoxonase/arylesterase activities in streptozotocin-induced diabetic rats. Sci World J 2014; 2014: 351-359.

56. Liu W, Hei Z, Nie H, Tang F, Huang H, Li X, Deng Y, Chen S, Guo F, Huang W. Berberine ameliorates renal injury in streptozotocin-induced diabetic rats by suppression of both oxidative stress and aldose reductase. Chin Med J 2008; 121: 706-711.

57. Devi PS, Kumar MS, Das SM. DNA damage protecting activity and free radical scavenging activity of anthocyanins from red Sorghum (Sorghum bicolor) Bran. Bio Res Int 2012; 2012: 1-9.

58. Cho J, Kang JS, Long PH, Jing J, Back Y, Chung K-S. Antioxidant and memory enhancing effects of purple sweet potato anthocyanin and cordyceps mushroom extract. Arch Pharm Res 2003; 26: 821-825.

\section{*Correspondence to}

Sibel Tas

Department of Biology

Arts and Sciences Faculty

Uludag University

Turkey

Nidal Jaradat

Department of Pharmacy

An-Najah National University

Palestine 